Document downloaded from:

http://hdl.handle.net/10251/64936

This paper must be cited as:

Hitzl, M.; Corma Canós, A.; Pomares Garcia, F.; Renz, M. (2015). The hydrothermal carbonization (HTC) plant as a decentral biorefinery for wet biomass. Catalysis Today. 257:154-159. doi:10.1016/j.cattod.2014.09.024.

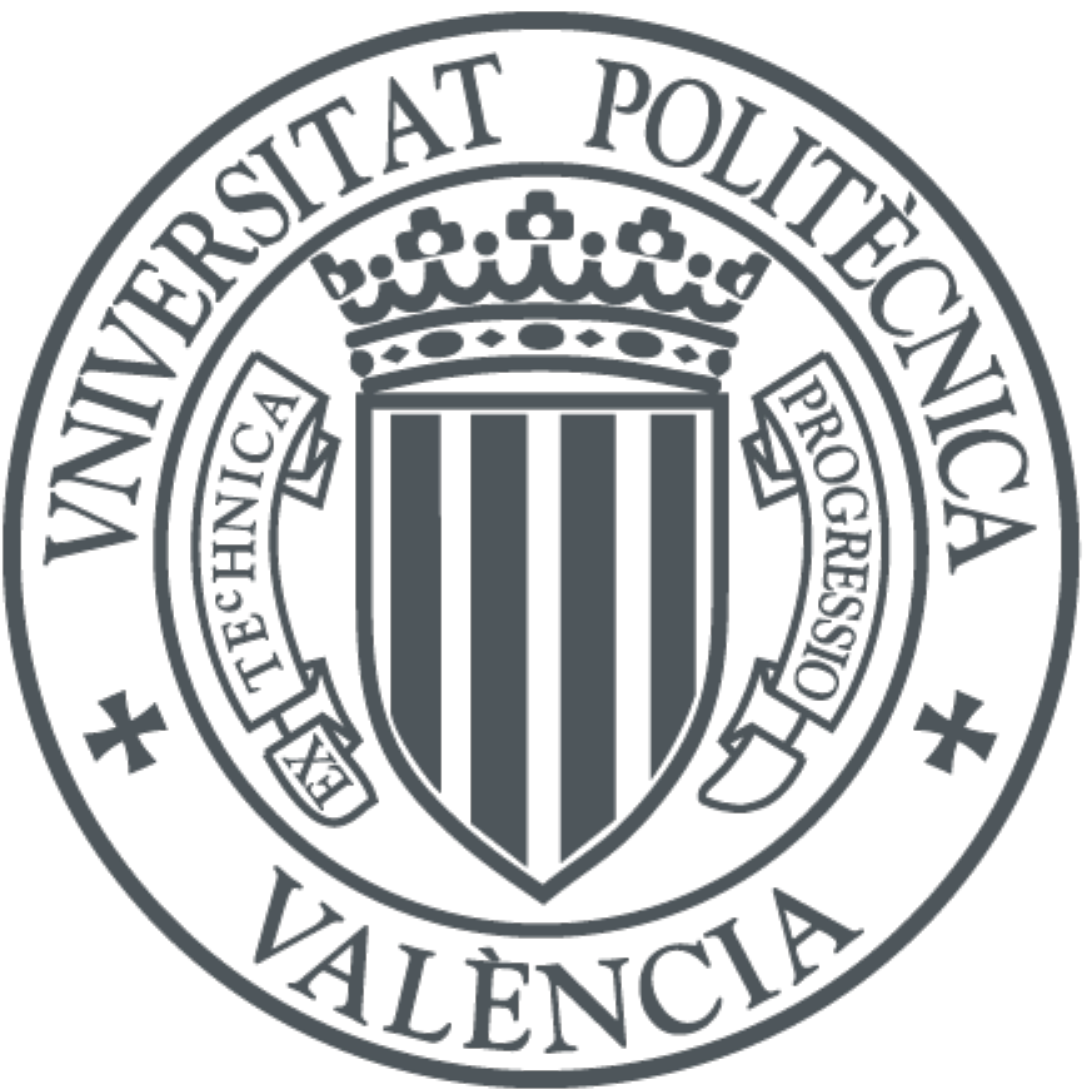

The final publication is available at

http://dx.doi.org/10.1016/j.cattod.2014.09.024

Copyright Elsevier

Additional Information 


\title{
The Hydrothermal Carbonization (HTC) plant as a decentral biorefinery for wet biomass
}

\author{
Martin Hitzl $^{\mathrm{a}, *}$, Avelino Corma $^{\mathrm{b}, *}$, Fernando Pomares $^{\mathrm{c}}$ and Michael Renz ${ }^{\mathrm{b}}$ \\ ${ }^{a}$ Ingelia, S.L., C/ Jaime Roig 19, 46010 Valencia, Spain \\ ${ }^{\mathrm{b}}$ Instituto de Tecnología Química, Universitat Politècnica de Valencia-Consejo \\ Superior de Investigaciones Científicas (UPV-CSIC), Avda. de los Naranjos s/n, 46022, \\ Valencia, Spain \\ ${ }^{c}$ Centro de Agricultura Sostenible, Instituto Valenciano de Investigaciones Agrarias \\ (IVIA), Apartado oficial, 46113 Moncada (Valencia), Spain \\ *martin.hitzl@ingelia.com, acorma@itq.upv.es
}

\begin{abstract}
The hydrothermal carbonization (HTC) is a very suitable process to transform wet biomass feedstocks into a peat-like material without drying the biomass input. Therefore, the energetic balance is more favorable than for alternative processes converting biomass as a whole. Further synergies can be achieved when the plant is employed as central hub for a regional biorefinery. Hence, a HTC pilot plant is operated with garden prunings and monitored during two years. It is shown that the elemental composition of HTC carbon is relatively constant. A carbon content of higher than $60 \%$ (based on dry, ash-free matter) is achieved. Fixed carbon content and volatile matter show low variation being the volatile content quite high with $61 \%$ on average. Dried in a post-process treatment which is less energy-demanding than drying of the raw biomass and pressed into pellets or briquettes the HTC carbon can be used as solid biofuel fulfilling the European standard (EN 14961-6).

With a regional thermal valorization of the biofuel the ashes can be returned as phosphorous source to the crop land from which the biomass was harvested. Part of the process water, which involves a high amount of potassium, can be used for crop irrigation. In this way, valuable plant nutrients are recovered for soil remediation. Hence, closing the nutrient cycles a HTC plant can be considered as a sustainable local biorefinery producing a solid biofuel. Thereby, solar energy is exploited which was
\end{abstract}

\footnotetext{
* Corresponding author. Tel.: +34 657837038 (M. Hitzl), +34 963877800 (A. Corma). E-mail address: martin.hitzl@ingelia.com (M. Hitzl), acorma@itq.upv.es (A. Corma).
} 
fixed before by photosynthesis together with the carbon dioxide which is liberated in the combustion of the solid biofuel. Optionally, the process water might serve as an alternative source of energy as it is demonstrated that its carbon content can be exploited for biogas production. 


\section{Graphical Abstract}

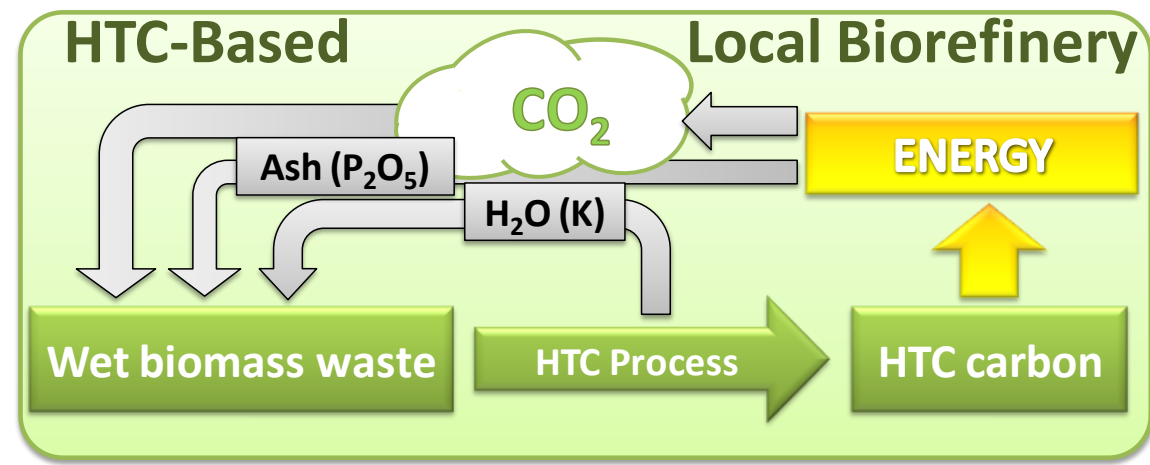

\section{Highlights}

The hydrothermal carbonization process was monitored in a pilot plant over two years HTC carbon fulfills European standard for a type of solid biofuel

HTC carbon ashes from garden prunings serve as source for plant nutrients (phosphorous)

Potassium levels in the soil can be improved by irrigation with HTC process water

Chemical oxygen demand of the process water can be reduced by $95 \%$ by biogas production

\section{Keywords}

biogas, biomass, carbonization, phosphorous, plant nutrient, potassium, solid biofuel 


\section{Introduction}

The biorefinery concept using biomass as feedstock for new sustainable chemicals and fuels requires a different methodology with respect to raw materials. The conventional petrochemical approach uses a big, concentrated, and continuous raw material stream to transform it into different products and by-products which are used as feed for subsequent processes [1]. Up scaling reduces production costs and therefore big facilities dominate the business [2].

Collecting biomass on the surface of our planet is labor-intensive, is exposed to variable productivity due to seasonal growing patterns and is limited to a certain amount available per surface unit [3]. Hence, for larger biomass amounts large surface areas have to be harvested [3]. Furthermore, transportation costs for taking biomass to big plants increases with the distance between the collection place and the processing plant [4]. In this respect, and in contrast to the conventional petroleum refinery, small local plants provide better economical balances due to the minimization of transportation costs [2]. On the other hand, standard properties or requirements of the biomass employed for biorefinery plants have to be defined. In most cases biomass is a heterogeneous mixture and a certain process can only transform part of it and others remain. For economical reasons the unexploited part should be a minor one [5]. A prominent example here is the production of bioethanol from lignocellulose. The latter is a biopolymer composite of cellulose, hemicellulose and lignin. Here, only the parts consisting of glucose units, i.e. cellulose and partly hemicellulose, can be exploited and the rest has to be discarded or revaluated differently [5].

A very attractive process for a biorefinery is the hydrothermal carbonization (HTC). Rediscovered in 2007 by Antonietti [6,7] originally the HTC process has been introduced by Bergius 1913 when working on coal liquefaction [8]. The solid HTC product is a peat like coal which is also often observed as an undesired by-product when monosaccharides (glucose, xylose, etc.) are employed in organic reactions and denominated humic acids or humins. Although formatino process conditions might differ, these humins are formed by dehydration and polymerization of carbohydrates and the same happens during the HTC process which is a physical and chemical dehydration process of lignocellulosic biomass. Hence, cellulose and hemicellulose are hydrolyzed to monosaccharides and disaccharides. These are dehydrated and polymerized again $[9,10]$. The application of HTC carbon as solid fuel is the first choice [11]. Other potential applications involve their transformation into active carbon or 
battery electrodes [12]. It might also be used as soil conditioner or for carbon sequestration $[13,14]$.

The HTC process is carried out in aqueous conditions at 180 to $250{ }^{\circ} \mathrm{C}$ at autogenous pressure. For the production of a solid biofuel the process water can be reduced to $50 \%$ by mechanical dewatering (Figure 1). After further thermal drying to a water content the HTC carbon can be pelletized.

Figure 1. Flow diagram from the wet biomass to HTC-carbon pellets as solid fuel processing the wet biomass by hydrothermal carbonization.

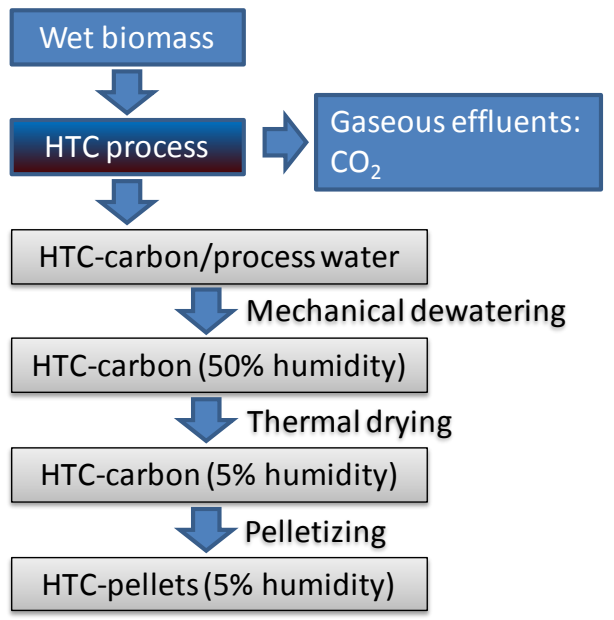

Apart from the fact that any lignocellulosic biomass can be processed, these aqueous conditions are the most significant advantage of the transformation since biomass always contains water (up to between $50 \%$ and $90 \%$; Table 1). For the HTC process biomass does not have to be dried by means of energy-consuming thermal processes (Figure 3). As the recalcitrant structure of the lignocellulose is partly destroyed during this process physical dehydration is facilitated for the solid product after the process. Hence, mechanical dewatering is possible down to below $50 \mathrm{wt} \%$ and thermal drying can eliminate the rest of the water. The mechanical dewatering saves energy since it is much less energy consuming than thermal drying as water does not have to be evaporated. Figure 2 illustrates how the energy saving occurs: The water content that has to be evaporated for the same dry matter is reduced to one fourth by mechanical means. Consequently, the transformation of biomass in the HTC process can be considered as a concentration of the carbon content in the biomass by chemical and physical (post-treatment) dehydration. 
Figure 2. Water amounts which have to be evaporated when drying materials with the same dry matter but with 80 or $50 \%$ of humidity. The water amount for $80 \%$ humidity is four-fold the amount for $50 \%$ humidity.

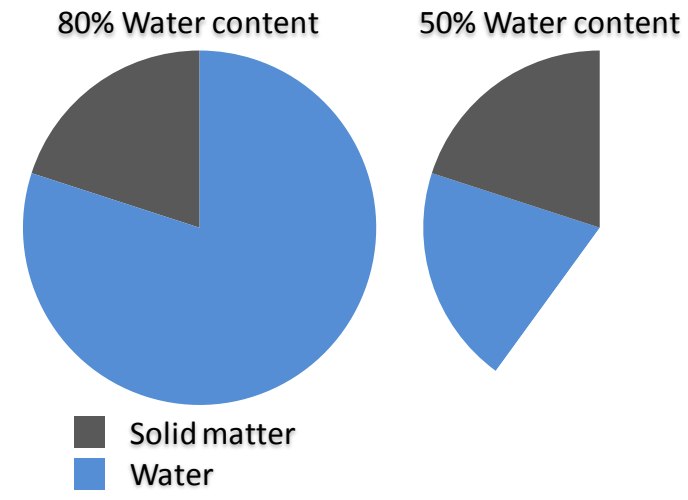

As any lignocellulosic material is accepted for the process, biomass waste streams can be processed, e.g. from agriculture, cellulose industry, agroindustry and even community residuals (e.g. municipal solid waste). The typical feedstock for a HTC plant consists of biomass waste streams characterized by high moisture content (up to 90 wt $\%$, cf. Table 1) and high content of impurities. Therefore, synergies might be achieved when the HTC process is combined with existing biomass exploitation activities and this would also ensure an interesting price structure for new coal products and by-products to be placed in the market.

Table 1. Water content of lignocellulosic biomass waste feedstocks.

\begin{tabular}{ll} 
Biomass feedstock & Water content/\% \\
\hline sugarcane bagasse & 50 \\
garden pruning & $30-80$ \\
organic fraction of municipal solid waste & $50-80$ \\
rice straw & 80 \\
orange peel & 86 \\
onion waste & 90 \\
\hline
\end{tabular}


Figure 3. Schematic description of the HTC process.

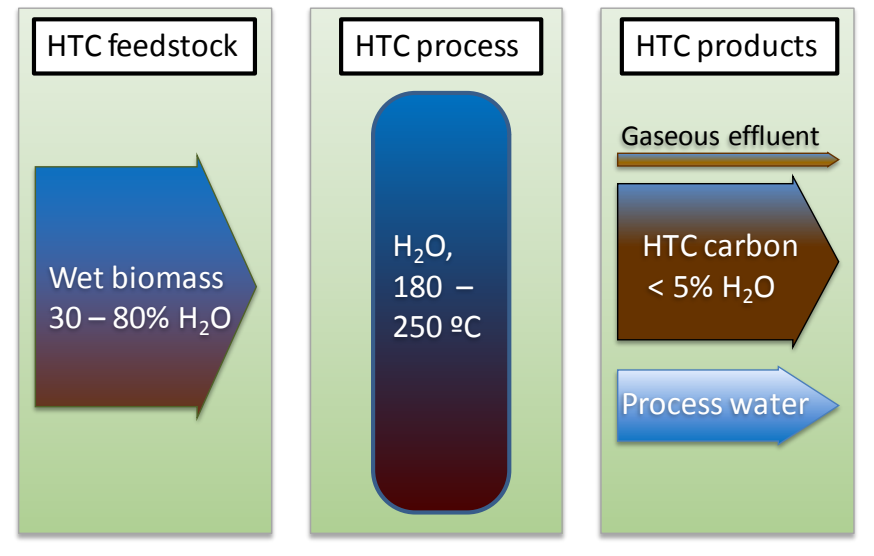

Herein, the suitability of the HTC process as a central hub for a biorefinery is evaluated at a pilot plant scale. Results obtained with the plant operated over three years are monitored and described for a period of two years. Solid products obtained from garden prunings are monitored during this time and analyzed with respect to a potential application as solid fuel. Aqueous effluents are analyzed with respect to its use for crop irrigation for the same period and also evaluated as a feed for biogas production. The ash of the HTC carbon will be evaluated upon its properties as soil conditioner. It will be seen that the HTC biorefinery provides decentralized transformation of biomass into a coal like raw material and other valuable products which can be locally integrated in closed sustainable cycles.

\section{Experimental Part}

The HTC process was carried out in a continuously operating HTC pilot plant (Figure 4) with a daily capacity of 1200-2400 kg of biomass (on dry base, between 8 and 16 hours operation time). The reactor shape is a vertical cylinder and wet biomass is fed to the reactor via a preheated tube to enter the reactor at reaction temperature $\left(>200{ }^{\circ} \mathrm{C}\right)$ at the bottom. The carbon outlet is also at the bottom and gases can be released at the top of the reactor. For the data presented mainly garden pruning biomass was processed. The solid product is separated from mainly inorganic particles (inorganic contaminations of the biomass fed, Figure 4, right hand side) and the process water is removed by filtration (down to below $50 \mathrm{wt} \%$ humidity). Afterwards, the HTC carbon can be dried thermally which is the most energy-consuming step of the post-treatment. The solid product was submitted to the following analysis procedures. The humidity was determined by the weight loss after heating to $100{ }^{\circ} \mathrm{C}$ for several hours. The ash 
content was measured by heating a crushed and sieved sample to $815^{\circ} \mathrm{C}$ in air for one hour (UNE 32-004-84) and the volatile content by heating a crushed and sieved sample to $900{ }^{\circ} \mathrm{C}$ in a closed vessel for $7 \mathrm{~min}$ (UNE 32-019-84). Fixed carbon content is calculated by the following formula: fixed carbon $/ \%=100-$ volatile content $/ \%-$ ash content $/ \%$. Elemental analysis of the HTC carbons $(\mathrm{C}, \mathrm{H}, \mathrm{N}, \mathrm{S})$ was performed on a Fisons EA 1108 CHNS-O. Data on the ash content, volatile content and elemental analysis are listed in Table S1. The composition of the ashes was analyzed by inductively-coupled plasma optical emission spectrometry (ICP-OES) on an ICPPlasma E15 after disaggregation in a $\mathrm{HF}-\mathrm{HNO}_{3}-\mathrm{HCl}$ solution.

Figure 4. Ingelia's HTC pilot plant (left hand side) and post-treatment facility (right hand side) involving ash reduction unit and mechanical dewatering down to below 50 wt $\%$ humidity.
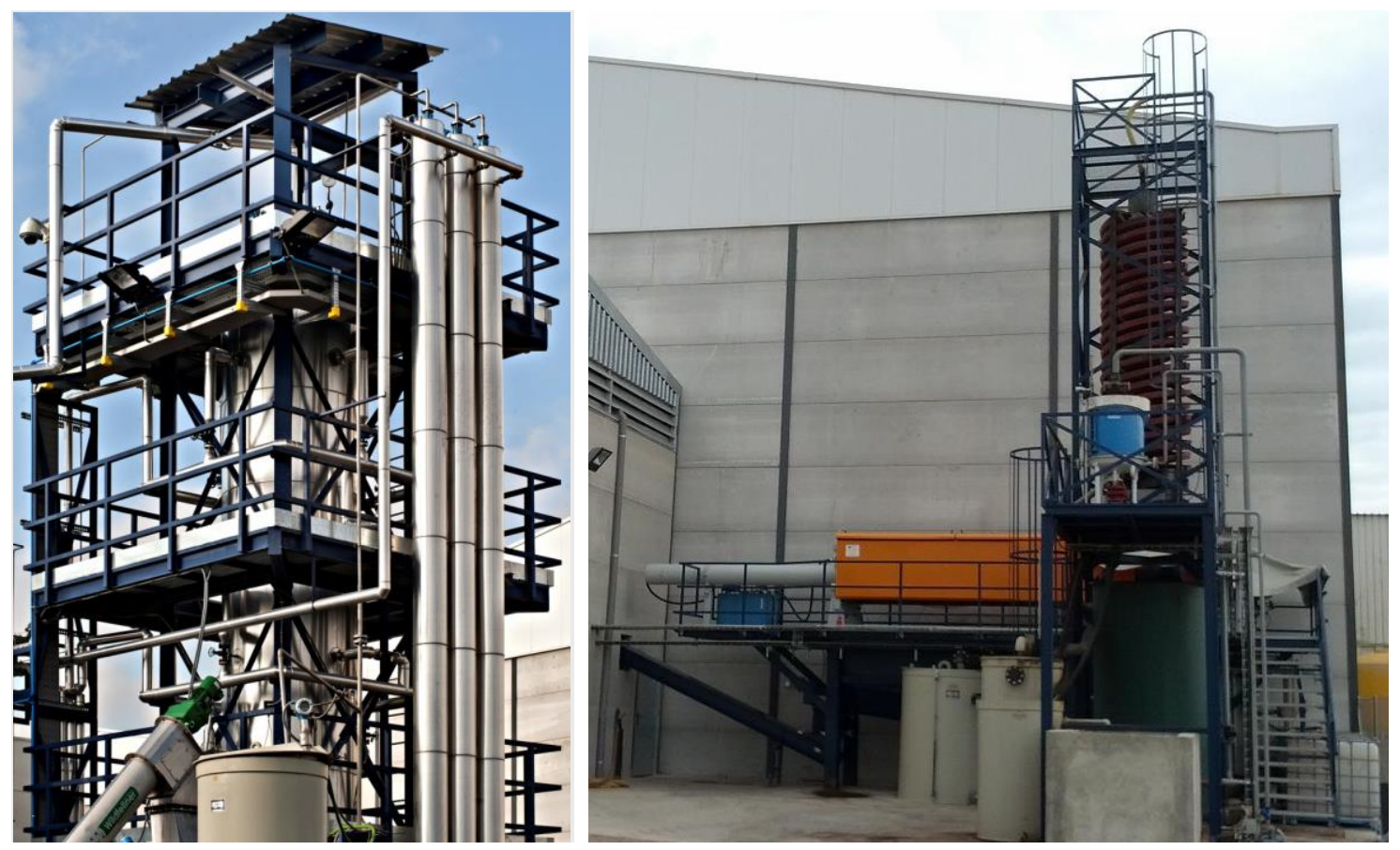

Process water analysis and monitoring was carried out by the Valencian Institute for Agricultural Research (IVIA). Samples were withdrawn over a period of two years and detailed analysis data with respect to its use for irrigation in a citric plantation can be found in Table S2.

The process water was studied as feed for biogas production at the "Sustainable Energy and Environmental Technologies (NEUTec)" Department of the University of Applied Science and Arts (HAWK, Göttingen, Germany) [15]. The water was passed through a 
cylindrical fixed-bed digester ( $64 \mathrm{~cm}$ high, $28 \mathrm{~cm}$ diameter). The fixed bed with a volume of $4.1 \mathrm{~L}$ and a surface area of $21 \mathrm{~m}^{2}$ was inoculated with the microorganisms and the water fed at a rate of $2 \mathrm{~L}$ to $10 \mathrm{~L}$ a day. This corresponds to a contact time of approximately three days with a loading per day of $10 \mathrm{~kg}_{\mathrm{COD}} /\left(\mathrm{V}_{\mathrm{wv}} \mathrm{x}\right.$ d) (COD: chemical oxygen demand; working volume $\left(\mathrm{V}_{\mathrm{wv}}\right)$ in $\mathrm{m}^{3}=$ total volume - catalyst support volume). Under these conditions a stable operation was achieved for a period of ten days.

\section{Results and Discussion}

The heart of the HTC pilot plant is a vertical pressurized cylinder in which the HTC process occurs. Biomass is pumped to this reaction chamber via a preheating tube and a rising tube so that it enters the cylinder at reaction temperature of more than $200{ }^{\circ} \mathrm{C}$. Depending on the physical properties of the biomass a mechanical pretreatment may be required. Soft biomass such as orange peel or onion waste is fed directly whereas garden prunings which include also small branches and wood pieces have to be shredded to a particle size of 5 to $10 \mathrm{~cm}$, and mixed with process water to get a pumpable slurry.

After a residence time of several hours the biomass has been transformed into HTC carbon and is removed from the bottom of the reaction chamber together with some process water. In the case that the water content of the biomass is low (e.g. $30 \mathrm{wt} \%$ ) process water is recycled to the process together with fresh biomass to improve the pumpability of the mixture.

In the post-treatment the HTC carbon is milled to a particle size of below $8 \mathrm{~mm}$ and inorganic particles removed by mechanical means. A filter press eliminates water down to a humidity content of 45 to $55 \mathrm{wt} \%$. Then the carbon powder can be further dried thermally and pressed into pellets or briquettes.

\section{Properties of the HTC carbon}

HTC-carbon samples were analyzed periodically during a period of 24 months. The chemical properties of the carbon are summarized in Table 2 and for all single data see Table S1. It can be seen that the composition of the solid product is relatively constant although the biomass input might change due to variations in the composition of the prunings or other seasonal alterations. The average carbon content was $61.5 \mathrm{wt} \%$. Carbon contents below $60 \mathrm{wt} \%$ are due to less severe process conditions. The average 
value can be considered as an indicator for successful biomass dehydration. In general, lignocellulosic biomass possesses a carbon content of approximately $45 \mathrm{wt} \%$ [16] which is raised to over $60 \mathrm{wt} \%$ by the HTC process. These values are always referred to the dry material on an ash-free basis. The average hydrogen content was $6.2 \mathrm{wt} \%$ which indicates roughly a $1: 1$ molar ratio of carbon and hydrogen. The nitrogen and sulfur content depends mainly on the content of the employed biomass and neither of them is modified significantly. When processing mainly garden prunings the nitrogen content varied between 1.0 and $2.4 \mathrm{wt} \%$ whereas the sulfur content was always below $0.2 \mathrm{wt} \%$.

Table 2. Summary of the elemental analysis (CHNS) and the proximate analyses of HTC carbon samples obtained in a period of 24 months from garden pruning biomass. For single data see Table S1.

\begin{tabular}{cccccccc} 
& $\mathrm{C}^{\mathrm{a}}$ & $\mathrm{H}^{\mathrm{a}}$ & $\mathrm{N}^{\mathrm{a}}$ & $\mathrm{S}^{\mathrm{a}}$ & Volatiles & Ashes & Fixed Carbon \\
Sample & {$[\%$ daf $]$} & {$[\%$ daf $]$} & {$[\%$ daf $]$} & {$[\%$ daf $]$} & {$[\%$ dry $]$} & {$[\%$ dry $]$} & {$[\%$ dry $]$} \\
\hline Average & 61.47 & 6.21 & 1.69 & 0.11 & 61.2 & 13.5 & 25.3 \\
Min. & 56.45 & 5.31 & 1.01 & 0.00 & 54.0 & 3.2 & 12.7 \\
Max. & 65.83 & 6.77 & 2.38 & 0.19 & 69.7 & 22.6 & 34.7 \\
\hline
\end{tabular}

${ }^{\mathrm{a}}$ On a dry and ash-free basis.

The proximate analysis of ash content, volatiles and fixed carbon is also summarized in Table 2. In comparison to fossil carbons the volatile part is relatively high varying between 54 and $70 \mathrm{wt} \%$ but it is still reduced when comparing with lignocellulosic biomass for which typical values (on a dry bases) fluctuate around $80 \mathrm{wt} \%$ [17]. On the other hand, the fixed carbon was low oscillating between 13 to $35 \mathrm{wt} \%$. Both ranges are typical for HTC carbons and have been observed also with other biomass types as feedstock. The ash content represents the water insoluble inorganic matter introduced with the biomass either as part of the original biomass or due to contamination (sand, dust, etc.) during harvesting and collection. With garden prunings the ash contents varied from 3 to $23 \mathrm{wt} \%$. Applying a post-treatment including floatation and gravity separation of particles with higher density due to the inorganic part, the ash content of the remaining carbon is reduced to below $10 \mathrm{wt} \%$. 
In summary, from the data presented it can be seen that, indeed, biomass is dehydrated during the HTC process. Carbon content is increased from $45 \mathrm{wt} \%$ to higher than 60 wt $\%$ and volatile content decreased to $61 \%$. If desired, an increased (chemical) dehydration could be achieved with more severe reaction conditions as for instance higher reaction temperature or prolonged residence times. The HTC carbon has interesting properties as solid biofuel. Table 3 compares HTC carbon pellet characteristics with the European standard of non-woody pellets for non-industrial use (EN 14961-6). This shows that the HTC process can transform a low grade biomass feedstock into a high density energy carrier. This type of high density pellet is water repellent and has a high resistance to fungus. One important characteristic is also the high ash fusion point in order to avoid clogging in boilers and stoves. In most cases the HTC carbon is suitable as solid biofuel as shown in Table 3. However, as biomass is a variable raw material, contents of single elements can exceed the established values. In this case suitable HTC carbons have to be mixed or the content lowered by other measures for its use as biofuel.

Table 3. Product properties of the HTC carbon as solid biofuel (obtained from garden prunings with a $50 \%$ humidity).

\begin{tabular}{|c|c|c|c|}
\hline Parameter & Unit & HTC carbon & EN 14961/6 \\
\hline Lower Heating Value (LCV) & $\mathrm{MJ} / \mathrm{kg}$ & $>23$ & \\
\hline Humidity & $\mathrm{wt} \%$ & $4-8$ & $<15$ \\
\hline Ashes & $\mathrm{wt} \%$ & $2-10$ & $<10$ \\
\hline Ash fusion point & ${ }^{\circ} \mathrm{C}$ & $>1200$ & \\
\hline Carbon (daf) ${ }^{\mathrm{a}}$ & $\mathrm{wt} \%$ & $>60$ & \\
\hline Hydrogen (daf) ${ }^{\mathrm{a}}$ & wt $\%$ & $5.8-6.2$ & \\
\hline Nitrogen (daf) ${ }^{\mathrm{a}}$ & wt $\%$ & $0.6-2.0$ & $<2$ \\
\hline Sulfur (daf) ${ }^{a}$ & $\mathrm{wt} \%$ & $<0.2$ & $<0.2$ \\
\hline Chlorine (daf) ${ }^{\mathrm{a}}$ & $\mathrm{wt} \%$ & $<0.2$ & $<0.3$ \\
\hline
\end{tabular}

${ }^{\mathrm{a}}$ On a dry and ash-free basis. 


\section{The local biorefinery concept}

For biomass exploitation small local plants help to save energy by minimizing transportation distances and this improves the overall process economics. However, the local biorefinery concept could achieve further synergies with respect to inorganic parts of the HTC carbon and inorganic and organic matter present in the process water. These materials can be considered as additional products of the process and need to be employed as fertilizer or soil conditioner in order to make the concept a sustainable one. Provided that HTC carbon is revalorized energetically the inorganic part of the carbon is recovered as ash. Hence, the composition of the ashes was explored to see if there was any interest when using them as fertilizer. For doing so several $\mathrm{kg}$ of HTC carbon were burned and the residue calcined $\left(815^{\circ} \mathrm{C}, 1 \mathrm{~h}\right)$ to obtain a representative and clean sample of the ashes. The composition of different metal oxides was determined by ICPOES. It can be seen that the three main components were silica, calcium oxide, and alumina ( 
Figure 5), which are also the representative components of dust in Spanish cities like Albacete and Barcelona [18]. Therefore, it can be concluded that a substantial part of the ashes were due to atmospheric contamination. However, also elements valuable for plant nutrition such as phosphorous and potassium were detected ( 
Figure 5). This demonstrated that part of the ashes arises from the biomass and this part can serve as a valuable inorganic fertilizer when returned to the crop land. Having in mind the short distances between harvesting areas and the local biorefinery plant the ash involving the nutrients can be returned to the soil from which the biomass has been obtained. This replenishes part of the inorganic matter (especially phosphorous) which had been consumed before by the plant growing.

As mentioned before, the HTC carbon is removed from the reactor together with water. The process water effluent is either introduced into the process as physically adsorbed water together with the biomass or as additional water which is needed for improving the pumpability when the biomass has a relatively low water content (30 to $60 \mathrm{wt} \%$ ). However, water is also generated by chemical dehydration. Between 20 and $30 \mathrm{wt} \%$ of dry mass of biomass can be converted into water for instance in the cellulose case. Therefore, water has to be considered as a product of the HTC process and has to be administrated. In the local biomass concept this water can be employed for crop irrigation. Thereby, again, valuable nutrients can be replenished in the soil. 
Figure 5. Composition of the ashes of HTC carbon obtained from garden prunings.

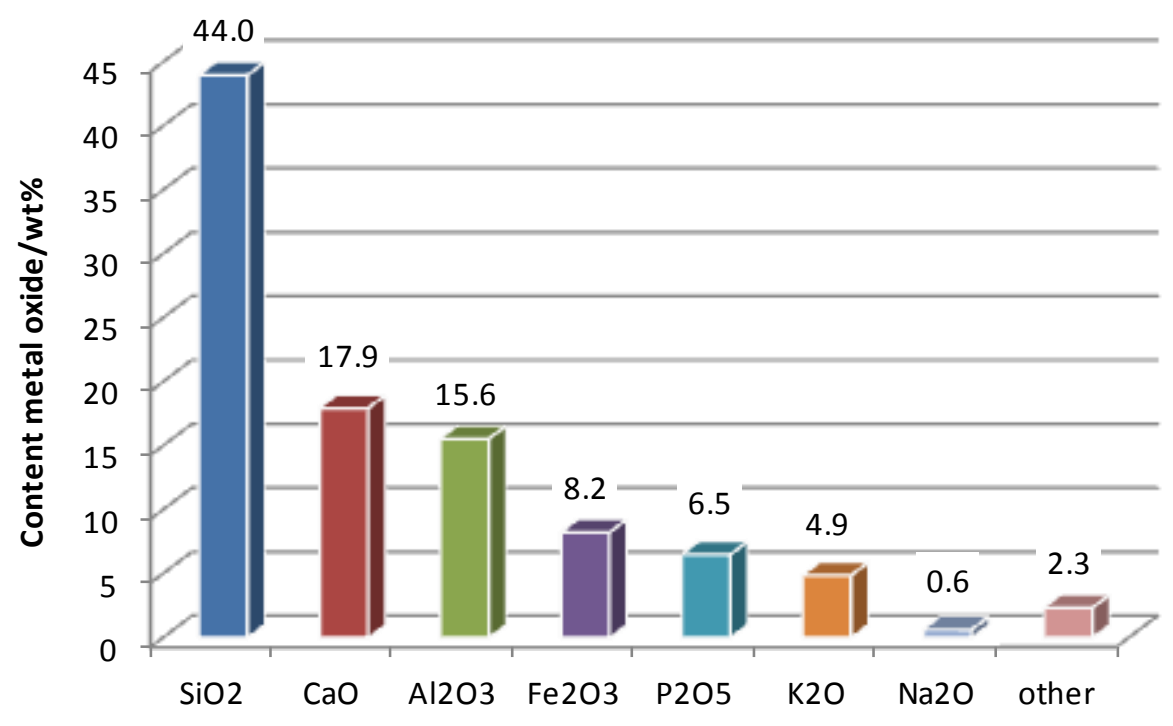

During a period of time of two years process water of the pilot plant was being monitored and used for irrigation. Table 4 summarizes the composition of the aqueous effluent, more detailed data can be found in Table S2. It can be seen that very small particles of the HTC carbon are not retained in the filter press and appear in the process water as sediments or humic extracts. However, the amount of total organic matter is bigger than the quantity of sediments. This means that there are also organic compounds dissolved in the water phase. By HPLC and MS short-chain carboxylic acids such as acetic acid, propanoic acid and butanoic acid were detected. Acetic acid might be derived from side chains in hemicellulose [16] and is often found as a product when biomass is processed as whole. These carboxylic acids also induce a weakly acidic $\mathrm{pH}$ as observed for the process water (5-7; Table S2).

For irrigation of a citric plantation the process water is supposed to be diluted by 1 to 40. In this way salinity (measured by electrical conductivity) and the concentration of phytotoxic elements such as boron and sodium are very low compared with the corresponding recommended maximum values (Table 4, upper part). On the other hand, even in this dilution, the process water contributes the required potassium amount. Probably, this is due to the good solubility of potassium salts in water. Hence, the HTC process acts as an effective extraction of potassium from the vegetable material. In contrast, in the case of less soluble elements or substances such as nitrogen- and phosphorous containing matter their concentration is lower. In the nitrogen case still $30 \%$ of the recommended amount is contributed whereas the phosphorous input is 
almost insignificant. This is in accordance with the fact that phosphorous pentoxide was found in a considerable fraction in the ashes $(6.5 \mathrm{wt} \%$, 
Figure 5). Hence, using the ash of the HTC carbon as a fertilizer is not only a way to get rid of the material but also combines again highly soluble and less soluble nutrients for soil remediation.

Process water was also analyzed for heavy metal contamination. However, as the main input for the HTC process was garden pruning or agro-industrial waste this kind of contamination was supposed to be low and this was also confirmed by the analysis.

Table 4. Important properties of the HTC process water with respect to its use for crop irrigation. Further details are listed in Table S2.

a) Pollutants with limited maximum concentrations for crop irrigation

\begin{tabular}{lcccccc} 
& Unit & Min. & Max. & Average & $1: 40^{\mathrm{a}}$ & Rec. max. $^{\mathrm{b}}$ \\
\hline Electrical conductivity & $\mathrm{dS} / \mathrm{m}$ & 6.8 & 16.8 & 11.4 & 0.285 & 1.6 \\
Boron $(\mathrm{B})$ & $\mathrm{ppm}$ & 1.7 & 4.4 & 2.9 & 0.073 & 1.0 \\
Sodium $\left(\mathrm{Na}_{2} \mathrm{O}\right)$ & $\mathrm{ppm}$ & 287 & 815 & 571 & 14.3 & 465
\end{tabular}

b) Soil remediation components

Per ha ${ }^{\mathrm{c}} \quad$ Recomm. $^{\mathrm{d}}$

Unit Min. Max. Average $\quad[\mathrm{kg}] \quad[\mathrm{kg}]$

\begin{tabular}{lcccccc}
\hline Organic matter & $\%$ & 0.78 & 2.36 & 1.66 & 2490 & \\
Total nitrogen & ppm & 191 & 746 & 490 & 73 & 240 \\
Phosphorous $\left(\mathrm{P}_{2} \mathrm{O}_{5}\right)$ & ppm & 6 & 30 & 18 & 2.7 & 80 \\
Potassium $\left(\mathrm{K}_{2} \mathrm{O}\right)$ & ppm & 503 & 2139 & 1306 & 195 & 150 \\
\hline
\end{tabular}

${ }^{\mathrm{a}}$ Concentration when diluted with water in an $1: 40$ ratio. ${ }^{\mathrm{b}}$ Recommended maximum concentration in the water for irrigation of a citric plantation. ${ }^{c}$ Amount of nutrient applied to one hectare when the process water is diluted in an 1:40 ratio for irrigation and $6000 \mathrm{~m}^{3}$ of total water is irrigated per hectare. ${ }^{\mathrm{d}}$ Recommended amount per hectare for a citric plantation.

In a second approach the process water from the hydrothermal carbonization of orange peel waste was used as a feed for a biogas production study. The combination of hydrothermal carbonization with the biogas production from the process water has been reported before [19]. The chemical oxygen demand (COD) of the process water was 23 
$-34 \mathrm{~g} / \mathrm{L}$ and it was fed to a fixed-bed digester with loadings of 1.5 and $10 \mathrm{~kg}_{\mathrm{COD}} /\left(\mathrm{V}_{\mathrm{wv}} \mathrm{x}\right.$

d) (Figure 6). These conditions correspond to contact times of 15 and 3 days, respectively. With the lower loading the COD is reduced to $5 \%$ of the initial value and $15 \mathrm{~L}$ of methane is produced per day. With the higher loading the methane production was raised to $90 \mathrm{~L}$ per day transforming the material which was responsible for $76 \%$ of the COD. For both conditions a stable operation was achieved for a period of ten days (Figure 6). This indicates that contact time can be chosen according to the preferred outcome. With a longer contact time the COD can be eliminated up to a high degree $(95 \%)$ or the methane production per day can be maximized with a small penalty due to decreased COD reduction. In summary, although based on a short trial the results obtained confirm that the biogas production can be an alternative to irrigation for the process water exploitation in the HTC process.

Figure 6. Results of the digestion of the HTC process water in a biogas plant.

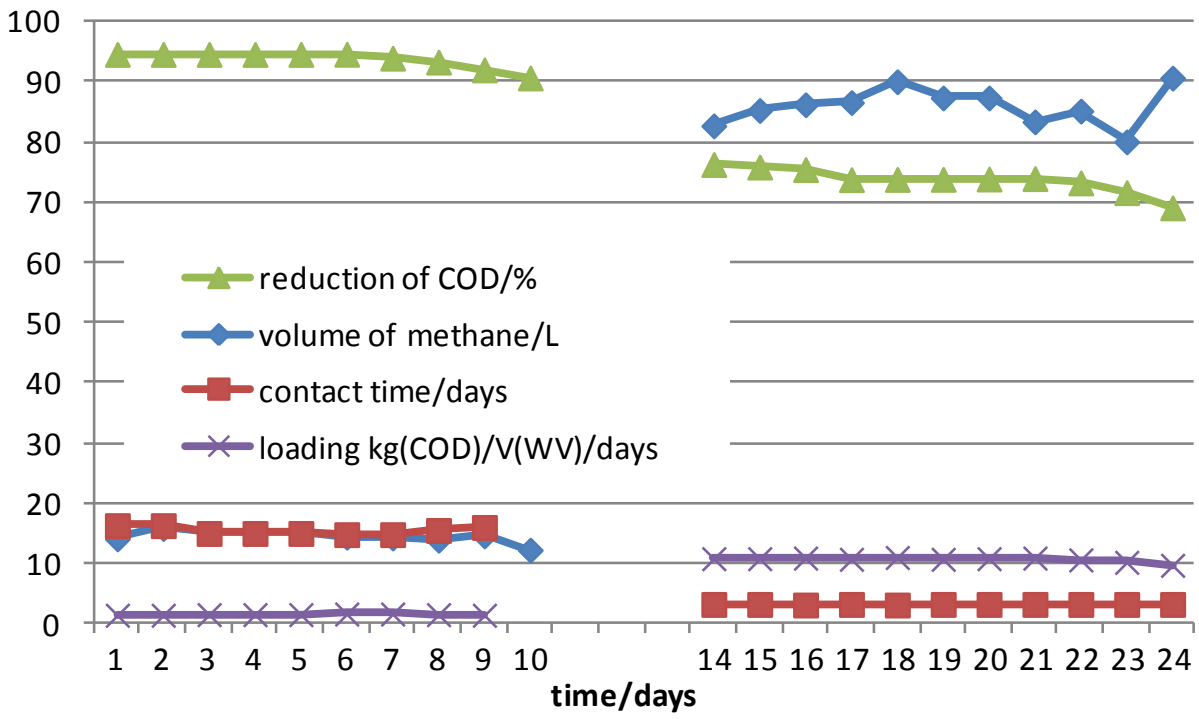

HTC carbon produced with the pilot plant is suitable as solid biofuel (Table 3) and it can be considered to be an energy carrier. Then for the HTC plant a closed cycle as described schematically in Figure 7 can be established. The carbon dioxide produced in the combustion had been removed before from the atmosphere as plant building blocks assimilated during the photosynthesis. A precise energy balance for the HTC pilot plant is being elaborated within the NEWAPP project and will be published [14].

Furthermore, for a local facility with local energetic valorization of the HTC carbon, the ash involving valuable nutrients can be recovered and replenish inorganic matter 
(phosphorous) consumed during plant growth. An additional source for plant nutrients, especially for soluble compounds (potassium, nitrogen in part from small carbon particles), is the process water which can be employed for crop irrigation. Additionally, by this use of the water carbon content missed by filtration is exploited and returned to the soil as humic material. Therefore, it can be concluded that all balances of materials can be closed in a local area. Below the line solar energy is converted into combustion energy employing wet lignocellulosic biomass waste as energy carrier. If, alternatively, this biomass waste feedstock was composted or landfilled, the same amount of energy would be released to the atmosphere by biological degradation without exploitation.

Figure 7. Schematic description of the HTC-based local Biorefinery concept involving local valorization of the solid HTC carbon product, using the ash as fertilizer and irrigation with the process water: a closed cycle is guaranteed for carbon dioxide as well as for plant nutrients.

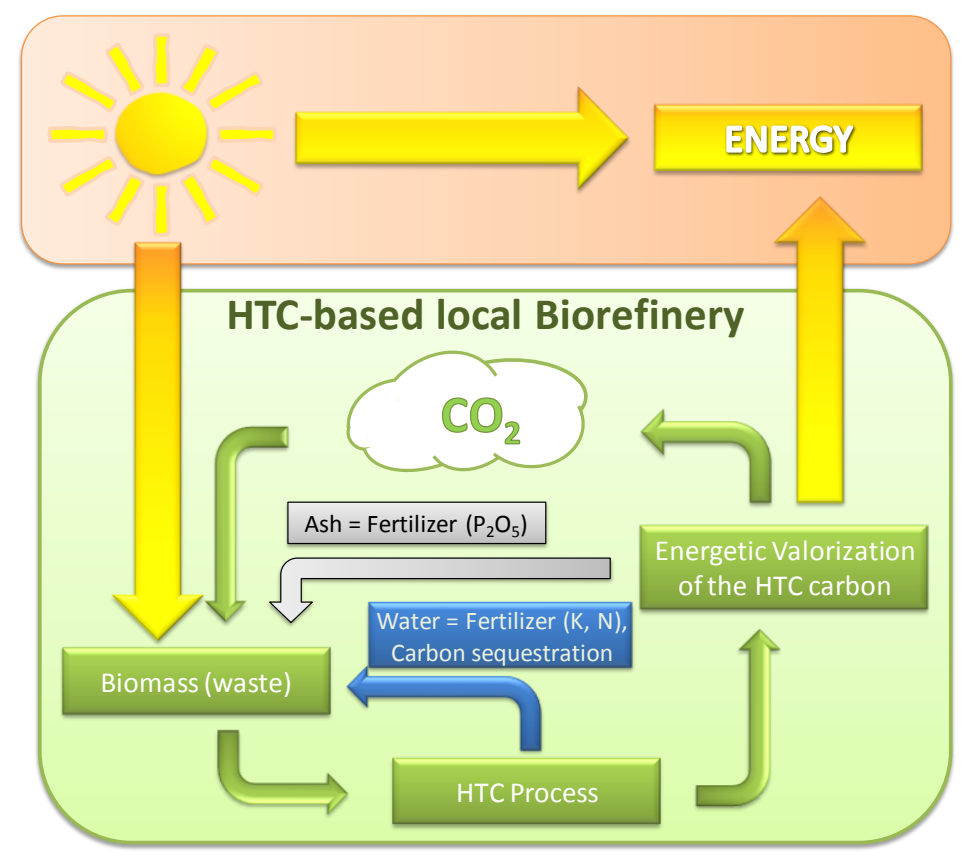

\section{Conclusions}

A HTC pilot plant working in continuous mode has been designed which permits to convert wet biomass waste feedstocks into HTC carbons. Due to the optimized design the size of the plant can be small and work still in an economically viable fashion. Hence, the HTC plant could serve as a local biorefinery, involving short transport distances from and to the plant, producing a solid biofuel for heat or electricity generation. Plant nutrients washed out during the process such as potassium can be 
recovered and used for soil fertilization by irrigation with the process water.

Phosphorous can be recovered in the ashes and returned to the crop land.

\section{Acknowledgement}

Authors are grateful for financial support obtained from the Spanish Ministry of

Economy and Competitiveness (Innpacto Programme, IPT-2012-0023-120000) and the European Union (FP7-SME-2013-605178-NEW APP).

\section{References}

[1] J. Speight, Petroleum (Refinery Processes) in Encyclopedia of Chemical Technology (Kirk-Othmer), Vol. 18, $4^{\text {th }}$ Edition, Wiley, 1996, p. 433.

[2] M. Wright, R. C. Brown, Biofuels, Bioprod. Bioref. 1 (2007) 191-200.

[3] S. Kromus, B. Kamm, M. Kamm, P. Fowler, M. Narodoslawsky, Green Biorefinery Raw Materials, in Biorefineries - Industrial Processes and Products, Eds.: B. Kamm, P. R. Gruber, M. Kamm, Wiley-VCH, 2006, p. 258.

[4] S. Sokhansanj, S. Mani, A. Turhollow, A. Kumar, D. Brandsby, L. Lynd, M. Laser, Biofuels, Bioprod. Bioref. 3 (2009) 124-141.

[5] Y. Pu, D. Zhang, P. M. Singh, A. J. Ragauskas, Biofuels, Bioprod. Bioref. 2 (2008) $58-73$.

[6] M. M. Titirici, A. Thomas, S.-H. Yu, J.-O. Müller, M. Antonietti, Chem. Mater. 19 (2007) 4205-4212.

[7] M. M. Titirici, A. Thomas, M. Antonietti, New J. Chem. 31 (2007) 787-789.

[8] F. Bergius, Nobel Lecture, 1932, http://www.nobelprize.org/nobel_prizes/chemistry/laureates/1931/bergius-lecture.html. [9] M.-M. Titirici, M. Antonietti, N. Baccile, Green Chem. 10 (2008) 1204-1212.

[10] N. Baccile, G. Laurent, F. Babonneau, F. Fayon, M.-M. Titirici, M. Antonietti, J. Phys. Chem. C 113 (2009) 9644-9654.

[11] N. D. Berge, C. Kammann, K. Ro, J. Libra, Potential Hydrochar Uses in Sustainable Carbon Materials from Hydrothermal Processes, M.-M. Titirici (Ed.), John Wiley \& Sons, Ltd, Chichester, UK, 2013, p. 308.

[12] M. Sevilla, A. B. Fuertes, R. Demir-Cakan, M.-M. Tirici, Applications of Hydrothermal Carbon in Modern Nanotechnology in Sustainable Carbon Materials from Hydrothermal Processes, M.-M. Titirici (Ed.), John Wiley \& Sons, Ltd, Chichester, UK, 2013, p. 213. 
[13] N. D. Berge, C. Kammann, K. Ro, J. Libra, Environmental Applications of Hydrothermal Carbonization Technology: Biochar Production, Carbon Sequestration, and Waste Conversion in Sustainable Carbon Materials from Hydrothermal Processes, M.-M. Titirici (Ed.), John Wiley \& Sons, Ltd, Chichester, UK, 2013, p. 295.

[14] http://www.newapp-project.eu/en/

[15] W. Ganagin, D. Neudeck, A. Loewen, Sustainable Energy and Environmental Technologies Department (NEUTec) of the University of Applied Science and Arts (HAWK, Göttingen, Germany), Final Report on the digestion of HTC process water in a fixed-bed digester, 2013.

[16] A. J. Ragauskas, M. Nagy, D. H. Kim, C. A. Eckert, J. P. Hallett, C. L. Liotta, Ind. Biotechnol., 2 (2006), 55-65.

[17] Y. Elmay, M. Jeguirim, S. Dorge, G. Trouvé, R. Said, Renew. Energ. 62 (2014) 209-215.

[18] T. Götschi, M. E. Hazenkamp-von Arx, J. Heinrich, R. Bono, P. Burney, B.

Forsberg, D. Jarvis, J. Maldonado, D. Norbäck, W. B. Stern, J. Sunyer, K. Torén, G.

Verlato, S. Villani, N. Künzli, Atmos. Environ. 39 (2005) 5947-5958.

[19] I. Oliveira, D. Blöhse, H.-G. Ramke, Biores. Technol. 142 (2013) 138-146. 


\section{The Hydrothermal Carbonization (HTC) plant as a decentral biorefinery for wet biomass}

Martin Hitzl ${ }^{\mathrm{a}} \uparrow$, Avelino Corma ${ }^{\mathrm{b}, *}$, Fernando Pomares ${ }^{\mathrm{c}}$ and Michael Renz ${ }^{\mathrm{b}}$

${ }^{a}$ Ingelia, S.L., C/ Jaime Roig 19; 46010 Valencia, Spain

${ }^{\mathrm{b}}$ Instituto de Tecnología Química, UPV-CSIC, Avda. de los Naranjos s/n, 46022,

Valencia, Spain

${ }^{\mathrm{c}}$ Centro de Agricultura Sostenible, Instituto Valenciano de Investigaciones Agrarias (IVIA), Apartado oficial, 46113 Moncada (Valencia), Spain

*martin.hitzl@ingelia.com, acorma@itq.upv.es

Table S1. Elemental analysis and composition of HTC carbon samples obtained in a period of 24 months processing mainly garden pruning biomass (in chronological order).

Table S2. Physical and chemical properties of the aqueous effluents of the HTC plant processing mainly garden pruning biomass.

† Corresponding author. Tel.: +34 657837038 (M. Hitzl), +34 963877800 (A. Corma).

E-mail address: martin.hitzl@ingelia.com (M. Hitzl), acorma@itq.upv.es (A. Corma). 
Table S1. Elemental analysis and composition of HTC carbon samples obtained in a period of 24 months processing mainly garden pruning biomass (in chronological order).

\begin{tabular}{|c|c|c|c|c|c|c|c|}
\hline Sample & $\begin{array}{c}\mathrm{C}^{\mathrm{a}} \\
{[\% \text { daf }]}\end{array}$ & $\begin{array}{c}\mathrm{H}^{\mathrm{a}} \\
{[\% \mathrm{daf}]}\end{array}$ & $\begin{array}{c}\mathrm{N}^{\mathrm{a}} \\
{[\% \text { daf] }}\end{array}$ & $\begin{array}{c}\mathrm{S}^{\mathrm{a}} \\
{[\% \text { daf }]}\end{array}$ & $\begin{array}{c}\text { Volatiles }^{\mathrm{b}} \\
\text { [\%dry] }\end{array}$ & $\begin{array}{l}\text { Ashes }{ }^{c} \\
{[\% \text { dry] }}\end{array}$ & $\begin{array}{c}\text { Fixed Carbon }{ }^{\mathrm{d}} \\
\text { [\%dry] }\end{array}$ \\
\hline 1 & 62.10 & 5.75 & 1.74 & 0.15 & 58.8 & 13.4 & 27.8 \\
\hline 2 & 59.83 & 5.59 & 1.71 & 0.17 & 54.0 & 21.0 & 25.0 \\
\hline 3 & 62.00 & 5.62 & 1.65 & 0.09 & 58.4 & 15.8 & 25.7 \\
\hline 4 & 56.45 & 5.31 & 1.21 & 0.10 & 59.4 & 10.4 & 30.3 \\
\hline 5 & 60.86 & 5.89 & 1.48 & 0.12 & 55.5 & 16.9 & 27.7 \\
\hline 6 & 58.30 & 5.52 & 1.11 & 0.10 & 62.1 & 3.2 & 34.7 \\
\hline 7 & 62.48 & 6.11 & 1.01 & 0.00 & 64.1 & 9.1 & 26.8 \\
\hline 8 & 63.59 & 6.54 & 2.16 & 0.17 & 56.7 & 21.2 & 22.1 \\
\hline 9 & 59.02 & 6.35 & 1.77 & 0.18 & 56.1 & 20.7 & 23.2 \\
\hline 10 & 63.51 & 6.60 & 2.13 & 0.19 & 56.2 & 22.3 & 21.6 \\
\hline 11 & 61.99 & 6.49 & 1.77 & 0.15 & 59.6 & 16.6 & 23.8 \\
\hline 12 & 62.64 & 6.20 & 1.46 & 0.00 & 69.7 & 17.6 & 12.7 \\
\hline 13 & 65.83 & 6.65 & 2.05 & 0.00 & 59.2 & 22.6 & 18.3 \\
\hline 14 & 61.28 & 6.35 & 1.32 & 0.14 & 63.9 & 12.9 & 23.2 \\
\hline 15 & 58.39 & 6.13 & 1.20 & 0.14 & 63.8 & 10.2 & 26.0 \\
\hline 16 & 63.95 & 6.12 & 1.50 & 0.12 & 62.8 & 10.2 & 27.0 \\
\hline 17 & 61.54 & 6.30 & 1.90 & 0.17 & 60.7 & 13.8 & 25.5 \\
\hline 18 & 64.17 & 6.38 & 2.08 & 0.14 & 60.0 & 12.5 & 27.4 \\
\hline 19 & 60.73 & 6.14 & 1.99 & 0.14 & 59.7 & 15.5 & 24.8 \\
\hline 20 & 61.12 & 6.60 & 1.98 & 0.17 & 61.8 & 14.2 & 24.0 \\
\hline 21 & 61.30 & 6.54 & 1.88 & 0.14 & 61.0 & 14.0 & 25.0 \\
\hline 22 & 61.14 & 6.41 & 1.98 & 0.12 & 61.8 & 13.6 & 24.6 \\
\hline 23 & 62.01 & 6.24 & 2.38 & 0.17 & 63.1 & 10.8 & 26.1 \\
\hline 24 & 60.83 & 6.20 & 1.86 & 0.00 & 62.6 & 9.2 & 28.2 \\
\hline 25 & 61.77 & 6.17 & 1.79 & 0.08 & 62.8 & 9.7 & 27.5 \\
\hline 26 & 62.60 & 5.99 & 1.75 & 0.00 & 61.6 & 12.0 & 26.4 \\
\hline 27 & 60.38 & 6.21 & 1.62 & 0.16 & 64.3 & 9.9 & 25.8 \\
\hline 28 & 60.55 & 6.37 & 1.93 & 0.12 & 63.3 & 14.2 & 22.6 \\
\hline 29 & 63.64 & 6.35 & 1.78 & 0.14 & 58.7 & 13.8 & 27.5 \\
\hline 30 & 62.67 & 6.40 & 1.59 & 0.15 & 60.8 & 12.7 & 26.5 \\
\hline 31 & 60.47 & 6.29 & 1.76 & 0.14 & 64.2 & 11.6 & 24.2 \\
\hline 32 & 60.77 & 6.21 & 1.63 & 0.08 & 64.4 & 9.3 & 26.3 \\
\hline 33 & 60.04 & 6.14 & 1.56 & 0.09 & 63.3 & 12.2 & 24.5 \\
\hline 34 & 62.56 & 6.77 & 1.34 & 0.07 & 63.0 & 9.5 & 27.5 \\
\hline 35 & 60.88 & 6.52 & 1.35 & 0.10 & 63.4 & 10.3 & 26.4 \\
\hline Average & 61.47 & 6.21 & 1.69 & 0.11 & 61.2 & 13.5 & 25.3 \\
\hline Min. & 56.45 & 5.31 & 1.01 & 0.00 & 54.0 & 3.2 & 12.7 \\
\hline Max. & 65.83 & 6.77 & 2.38 & 0.19 & 69.7 & 22.6 & 34.7 \\
\hline
\end{tabular}

${ }^{\mathrm{a}}$ On a dry and ash-free matter. ${ }^{\mathrm{b}}$ Volatiles is defined as the part of the carbon that is eliminated by heating a sample to $900{ }^{\circ} \mathrm{C}$ for seven minutes in absence of oxygen. ${ }^{\mathrm{c}}$ Ashes are the inorganic part which remains after combustion of the carbon sample at $815^{\circ} \mathrm{C}$ for one hour. ${ }^{\mathrm{d}}$ Fixed carbon is the organic part that is not characterized as volatile, i.e. that remains after heating the sample for seven minutes at $900{ }^{\circ} \mathrm{C}$ in absence of oxygen. 
Table S2. Physical and chemical properties of the aqueous effluents of the HTC plant processing mainly garden pruning biomass.

Samples

\begin{tabular}{|c|c|c|c|c|c|c|c|c|c|c|c|c|c|c|}
\hline Parameter & Unit & 1 & 2 & 3 & 4 & 5 & 6 & 7 & 8 & 9 & 10 & Average & Min. & Max. \\
\hline Dry matter & wt $\%$ & 1.76 & 2.20 & 3.61 & 3.06 & 2.57 & 3.19 & 2.70 & 2.20 & 1.80 & 1.70 & 2.48 & 1.70 & 3.61 \\
\hline Sediments & wt $\%$ & - & 0.70 & 0.86 & 0.78 & 0.70 & 0.45 & 0.93 & 0.39 & 0.37 & 0.74 & 0.66 & 0.37 & 0.93 \\
\hline Total organic matter & wt $\%$ & 1.13 & 1.55 & 2.55 & 2.15 & 1.83 & 1.99 & 2.10 & 0.78 & 1.26 & 1.22 & 1.66 & 0.78 & 2.55 \\
\hline Oxidizable organic matter & $\mathrm{wt} \%$ & 1.11 & 1.51 & 2.36 & 2.13 & 1.75 & 1.95 & 1.87 & 0.78 & 1.20 & 1.13 & 1.58 & 0.78 & 3.40 \\
\hline Oxidizable organic carbon & wt $\%$ & 0.64 & 0.87 & 1.37 & 1.23 & 1.01 & 1.13 & 1.08 & 0.45 & 0.70 & 0.66 & 0.91 & 0.45 & 1.37 \\
\hline Total humic extract & wt $\%$ & - & 1.38 & 2.17 & 2.01 & 1.68 & 1.89 & 1.84 & 0.70 & 1.06 & 1.00 & 1.53 & 0.70 & 2.17 \\
\hline $\mathrm{pH}$ & & 5.78 & 6.45 & 5.73 & 6.91 & 6.28 & 5.32 & 6.13 & 6.96 & 5.12 & 6.19 & 6.09 & 5.12 & 6.96 \\
\hline Total nitrogen & ppm & 345 & 490 & 746 & 717 & 608 & 694 & 564 & 191 & 282 & 265 & 490 & 191 & 746 \\
\hline Ammonia & ppm & 18 & 87 & 89 & 132 & 97 & 80 & 31 & 10 & 38 & 15 & 60 & 10 & 132 \\
\hline Nitrate & ppm & 1 & 3 & 4 & 5 & 4 & 5 & 3 & 1 & 2 & 1 & 3 & 1 & 5 \\
\hline $\mathrm{C} / \mathrm{N}$ ratio & & 19 & 18 & 18 & 17 & 17 & 16 & 19 & 24 & 25 & 25 & 20 & 16 & 25 \\
\hline Electrical conductivity & $\mathrm{dS} / \mathrm{m}$ & 7.5 & 10.5 & 16.8 & 16.2 & 13.6 & 14.4 & 12.9 & 6.8 & 7.8 & 7.4 & 11.4 & 6.8 & 16.8 \\
\hline Boron (B) & ppm & 1.9 & 2.4 & 4.0 & 4.2 & 3.5 & 2.5 & 4.4 & 1.7 & 1.9 & 2.1 & 2.9 & 1.7 & 4.4 \\
\hline Phosphorous $\left(\mathrm{P}_{2} \mathrm{O}_{5}\right)$ & ppm & 30 & 17 & 21 & 11 & 15 & 19 & 14 & 6 & 19 & 25 & 18 & 6 & 30 \\
\hline Sodium $\left(\mathrm{Na}_{2} \mathrm{O}\right)$ & ppm & 530 & 563 & 747 & 815 & 666 & 718 & 729 & 343 & 287 & 314 & 571 & 287 & 815 \\
\hline Potassium $\left(\mathrm{K}_{2} \mathrm{O}\right)$ & ppm & 883 & 1158 & 2139 & 1982 & 1594 & 2134 & 1493 & 503 & 600 & 575 & 1306 & 503 & 2139 \\
\hline Magnesium (MgO) & ppm & 326 & 443 & 806 & 660 & 525 & 768 & 637 & 270 & 333 & 339 & 511 & 270 & 806 \\
\hline Calcium $(\mathrm{CaO})$ & ppm & 1656 & 2371 & 3384 & 3365 & 2695 & 3024 & 2680 & 1150 & 1390 & 1541 & 2326 & 1150 & 3384 \\
\hline Iron $\left(\mathrm{Fe}_{2} \mathrm{O}_{3}\right)$ & ppm & 9 & 15 & 25 & 14 & 11 & 12 & 26 & 15 & 11 & 51 & 19 & 9 & 51 \\
\hline
\end{tabular}


